\title{
Transactional Analysis Shows Child Factor Would be Influential Egogram for Late Teenager
} Yokoyama $\mathrm{T}^{\mathbf{1}}$ and Bando $\mathrm{H}^{\mathbf{2}^{*}}$

\section{Affiliation:}

${ }^{1}$ Dept. of Advanced Technology and Science, Tokushima University, Tokushima, Japan

${ }^{2}$ Tokushima University and Medical Research, Tokushima, Japan

*Corresponding author: Hiroshi BANDO, Tokushima University /Medical Research, Nakashowa 1-61, Tokushima 770-0943 Japan

TEL: +81-90-3187-2485, E-mail: pianomed@bronze.ocn.ne.jp

Citation: Yokoyama T and Bando $\mathrm{H}$. Transactional analysis shows child factor would be influential egogram for late teenager (2021)

Edelweiss Psyi OpenAccess 5: 7-9.

Received: Oct 10, 2021

Accepted: Dec 23, 2021

Published: Dec 31, 2021

Copyright: (ㅇ 2021 Yokoyama T, et al., This is an open-access article distributed under the terms of the Creative Commons Attribution License, which permits unrestricted use, distribution, and reproduction in any medium, provided the original author and source are credited.

\begin{abstract}
Background: Transactional Analysis (TA) and egogram have been in focus for medical and educational fields. There has been a reliable personality battery, Tokyo University Egogram (TEG). Recent topic includes TEG new version 3 for clinical introduction. Using TEG ver.3, university students were investigated for their egogram pattern. Subjects \& Methods: Subjects were 99 late teenagers. They were given lectures of TEG and their data was analyzed three months after the admission of the university. Results: TEG ver3 presents 33 egogram types which are related to the personality of Japanese people. Among them, there were four higher prevalence of egogram types, which were Free Child (FC) dominant, Adapted Child (AC) dominant, Critical Parent (CP) inferior and Child (C) Dominant. The percentage datum of current study $v s$ previous standard value in each type was 10 vs $6.8 \%, 26$ vs $6.1 \%, 8$ vs $2.1 \% 9$ vs $1.1 \%$, respectively. Discussion \& Conclusion: These four types are estimated as free-spirit, dependent, loose and selfishness. Elevated FC and AC would be probably due to the influence of educational and social environment in Japan. Among them, high school students must study hard for entrance exams without meaningful social experiences. Further investigation will be required for TEG.
\end{abstract}

Keywords: Transactional analysis, Tokyo University Egogram, Egogram, Free Child, Adapted Child.

\section{Introduction}

For decades, behavioral science, psychology and psychiatry have been more important in social circumstances [1]. One reason includes increased stress, which may influence the personality of the people [2]. Consequently, some perspective would be required in the light of communication, Transactional Analysis (TA), ego, egogram, and so on. From an ethical and psychological point of view, ego has meant the consciousness concerning empirical individuality [3xx](Berne-1957). Furthermore, ego also means a conscious personality which can keep contact with the reality and mediate super ego psychoanalytically $[3,4]$. TA was originally presented by Berne [5]. Formerly, the behavior or activity of people was thought to include fie ego conditions such as voice, language, action, expression, and gesture/posture. After that, Dusay became a disciple of Berne, who graphed these egos [6]. Everybody can easily understand the status of egos visually, including Critical Parent (CP), Nurturing Parent (NP), Adult (A), Free Child (FC) and Adapted Child (AC). By a series of working for egogram, one can understand and know the presence of our egos. It makes to give us the power to respond to a variety of stressors in our daily lives and to control of our minds psychologically [7].

Authors have continued the study of egograms for various subjects and patients $[8,9]$. As regards to the egogram, the Tokyo University Egogram (TEG) 2nd edition has been widely used for long, which was proposed by psychosomatic department of Tokyo University in Japan [10]. In our previous report, the target subjects included university students and others. For the analysis of the results, some reports have been published so far [11].
After clinical and educational applications of TEG $2^{\text {nd }}$ edition for years, new edition of TEG has been recently introduced [12]. Our research group always gives lecture and research on TEG in various opportunities. We have investigated egogram status for university students, and analyzed. The results and some discussion will be presented in this article.

\section{Subjects and Methods}

The subjects for current research were late teenagers who were firstyear university students $(n=99)$. They entered the Faculty of Science and Technology, Tokushima University, one of the national universities in Japan. They included 49 students $(M / F=45 / 4)$ enrolled in 2020 and 50 students $(\mathrm{M} / \mathrm{F}=46 / 4)$ in 2021. Regarding the research method, the authors have given TEG lectures to university students in every year. Simultaneously, we have analyzed the egogram data from the students at that time. The lectures related to this research were provided in July 2020 and July 2021. In Japan, April is the time to enter the university, and then it is rather stable situation for the students for three months. The battery used in this research was Tokyo University Egogram (TEG) ver3. TEG has been a reliable test method for egogram in the clinical research for years. Authors have conducted TEG ver.2 on many cases and reported the research results from psychological point of view. TEG Ver.3 is the new version announced in December 2019 [12]. It includes 53 question items, and takes about 10 minutes for answering and about 5 minutes for scoring [13]. In 
Japan, it has been recognized as one of the useful battery in the medical, social and educational fields.

\section{Results}

The results of performing TEG ver3 on 99 university students were shown in Table 1. Among them, some common types are observed which showed more prevalence in comparison with standard ratio [10]. They are 1) AC dominant: dependent type $(\mathrm{n}=26), 2)$ FC dominant: free-spirit type $(n=10), 3)$ CP inferior: loose type $(n=8)$ and 4) C dominant: selfishness type $(n=9)$. For general tendency of these data, the characteristic aspect of student ego was closer to $\mathrm{C}$ (Child predominance) with a particularly high $\mathrm{AC}$ result [11]. These four types were estimated to be rather specific personality in Japanese people, which are 1) free-spirit, 2) dependent, 3) loose and 4) selfishness. Elevated FC and AC would be probably due to the influence of educational and social environment in Japan. Among them, high school students must study hard for entrance exams without meaningful social experiences. Further investigation will be required for TEG.

\begin{tabular}{|c|c|c|}
\hline Classification of types & Students & Standard \\
\hline Egogram types & $(\%)$ & $(\%)$ \\
\hline \multicolumn{3}{|l|}{ Dominant type } \\
\hline CP dominant & 2 & 3.4 \\
\hline NP dominant & 2 & 7.7 \\
\hline A dominant & 4 & 8.1 \\
\hline FC dominant & 10 & 6.8 \\
\hline AC dominant & 26 & 6.1 \\
\hline \multicolumn{3}{|l|}{ Inferior type } \\
\hline $\mathrm{CP}$ inferior & 8 & 2.1 \\
\hline NP inferior & 2 & 2.8 \\
\hline A inferior & 6 & 4.8 \\
\hline FC inferior & 2 & 4.7 \\
\hline AC inferior & 3 & 3.1 \\
\hline \multicolumn{3}{|l|}{ Mixed type } \\
\hline Trapezoidal (NP, A, FC High) & 2 & 3.5 \\
\hline Trapezoidal (NP, A, High) & 0 & 1.2 \\
\hline Trapezoidal (A, FC High) & 2 & 1.8 \\
\hline U Type (NP, A, FC Low) & 2 & 2.6 \\
\hline U Type (NP, A, Low) & 0 & 1.1 \\
\hline U Type (A, FC Low) & 2 & 1.1 \\
\hline N Type (A Low) & 2 & 4.1 \\
\hline N Type (NP High, FC Low) & 0 & 4.1 \\
\hline N Type (A High) & 3 & 1.8 \\
\hline Inverse N (A High) & 0 & 4 \\
\hline Inverse N (NP Low, FC High) & 0 & 3.2 \\
\hline Inverse N (A Low) & 1 & 1.9 \\
\hline M Type & 2 & 5.5 \\
\hline W Type & 0 & 3.3 \\
\hline Flat low level Type & 0 & 1.4 \\
\hline Flat middle level Type & 3 & 7.4 \\
\hline Flat high level Type & 0 & 0.3 \\
\hline P Dominant & 0 & 0.9 \\
\hline C Dominant & 9 & 1.1 \\
\hline N Type (I \& II mixed) & 4 & - \\
\hline N Type (II \& III mixed) & 1 & - \\
\hline Inv N Type (I \& II mix) & 0 & - \\
\hline Inv N Type (II \& III mix) & 1 & - \\
\hline
\end{tabular}

Table 1: Classification of egogram types.

\section{Discussion}

Egogram has traditionally made various contributions in the field of psychology [14]. It is involved in appropriate language strokes in social life for various interactions with people. This survey was conducted about three months after the admission of the university. It seemed to be psychologically and socially stable period [15]. Increased prevalence of egogram types were found in current study, which were FC dominant, AC dominant, $\mathrm{CP}$ inferior and C Dominant. They seem to be estimated as free-spirit, dependent, loose and selfishness. From obtained results, the characteristics seemed to be generally related to factor C [16]. From this point of view, some discussion will be described in this article.

First, factor $\mathrm{C}$ is a child factor. After graduating from high school, the students are 18-19 years old, which are equivalent to the latter half of teenagers [17]. They are still socially immature during this period. If the students become 3 rd or 4th grade, they will have enough experiences to decide various matters. For campus life for only 3 months, however, they do not have such experiences yet. Therefore, it is considered that the child factor still has a strong influence to their personality. Next, the result showed that AC factor is high. In recent years, certain characteristics have been pointed out when Japanese students have campus lives from elementary school to senior high school. At school, the students are required to act in some class or group units, and then selfish acts that disturb the group behavior are subject to some criticism [18]. Therefore, average students have been accustomed to adaptation for the atmosphere for personal communication.

Second, factor AC has been elevated as shown in this result, which is probably due to educational and social environment in Japan [11]. Another feature would be included that FC was elevated. After 3 months after the admission of the university, students are excited about their new university life. Especially in Japan, it would be the period that they are released from studying hard for entrance exams. For this reason, they have probably received the advance information that college life is generally enjoyable without any obligation. However, during 2020-2021, crucial problem of COVID-19 has been persisting in the world. Due to continuous self-restraint, they cannot enjoy campus lives as usual. Consequently, some additional circumstances would be considered.

Consequently, the egogram results of most students appear to be heavily influenced by factor $\mathrm{C}$. From the viewpoint of education, it is not enough to simply leave it to the independence of students [8]. Rather, it seems that the instructor needs to instruct students in a detailed manner. Without it, students may be confused by the new environment or may not be able to cope well with daily new life. In the light of university instructors, it seems necessary to firmly support university life while fostering student independence.

The new TEG ver $3 *$ revision has same 29 kinds of conventional type classification [13]. However, some cases were belonged to borderline of two types. They were four borderline types, including "N type I / II mixed type", "N type II / III mixed type", "Inverted N type I / II mixed type", and "Inverted $\mathrm{N}$ type II/ III mixed type" [12]. They seemed to be mixed types, then; it is rather difficult to make decision which to be categorized. Consequently, additional four types are inserted in the Table 1. As we continue to accumulate such cases, some perspective will be obtained in the future.

In current study, four common types that were observed in current research would be discussed. The major different patterns between students and general people were 1) FC dominant type, 2) AC dominant type, 3) $\mathrm{C}$ dominant type, and 4) $\mathrm{CP}$ low type. These showed higher prevalence rate than the general public. From the viewpoints of types $1,2,3)$, almost half students showed strongly-expressed child ego [17]. In other words, freshman (1st year) students still have strong child's ego and need for guidance and support from university instructors. Therefore, it would be required for the students to be get used to daily life and independence situation. The highest prevalence was observed in 2) AC dominant type. Since the pattern that is dependent to others occupies about a quarter, it is adequate to observe carefully various behaviors of the children, when leaving their parents. The reason would be that the university environment has a high degree of freedom, and is therefore likely to be involved in dangerous matters. Particular attention should be paid to highly dependent items such as alcohol, smoking, drugs and gambling, and early guidance and education are considered necessary for them [19]. 
Furthermore, 4) CP low-level type was higher than that of the general public. Since the average value of CP is lower, the loose and sloppy personal character may bring carelessness behavior. Therefore, there may be risky opportunities of receiving dangerous matter without refusing. Especially in the case of low $\mathrm{CP}$ and high $\mathrm{AC}$, it is easy to fall into some temptation in the new environment. In addition, with FC-dominant character, the students will be involved in dangerous matters by themselves due to their curiosity. Similarly, the egogram type with low CP, high FC, and low A needs special attention [20].

As described above, it is considered necessary to intervene by education and guidance on the results of student egograms. The low CP value is also related to the failure to meet the deadline for submitting reports. Every year, 10 to $20 \%$ of students do not submit even after the deadline. Unless the instructor does not mention that the report has not been submitted, the student does not consider. It is a crucial problem for students to enter usual society associated with such attitudes and situations [21]. The observance of various rules would be the fundamental. It is essential to give guidance to such students to recognize the harsh reality, such as giving a penalty.

FC factors are generally found at high levels in the subject of university students. For this reason, two groups would be probably present in the students. Group1 includes students who showed increased FC factor by releasing from the suppressed state in the high school. Group 2 includes students who showed stable FC factor level as before. This is difficult to compare because there are no data of egograms a few years ago when they were high school students [22]. In our study, however, there was a case who showed rapid increase of FC factor, after several months of entering the university.

From the above, it is suggested that the value of FC may change significantly in a relatively short period of time by enrolling in a free student life [23]. The authors speculate that FC change would be larger when compared to just a few months after entering university [21]. A comparative study can be possible in two groups, one with FC changes and one with no change. Several reasons may be involved in the difference, such as whether the subject can be accustomed to the school life and friends, whether he lives with his parent or only himself, whether some differences are present in club activities or curriculum $[22,23]$.

If the situation permits, more detailed investigations can be possible. Then, interesting results may be obtained if there is basic research, follow-up research, counseling and so on. This study has some limits. The number of cases (male/female) is small and especially the number of female is especially small. Then, it is difficult to compare the data statistically. Further investigation will be required for university students to consider relationship with various differences in age and specialty.

\section{Conclusion}

A new version of TEG was applied to university students for study of the detail egogram. Compared with conventional standard data, four common egogram types were obtained. Future study will be necessary to accumulate and compare various data of egogram, leading to satisfactory communication situation.

\section{References}

1. O'Connor DB, Thayer JF and Vedhara K. Stress and Health: A Review of Psychobiological Processes (2021) Annu Rev Psychol 72: 663-688. https://doi.org/10.1146/annurev-psych-062520$\underline{122331}$

2. Li Q, Yan J, Liao J, Zhang X, Liu L, et al. Distinct Effects of Social Stress on Working Memory in Obsessive-Compulsive
Disorder (2021) Neurosci Bull 37: 81-93. https://doi.org/10.1007/s12264-020-00579-3

3. Berne E. Ego states in psychotherapy (1957) Am J Psychother 11: 293-309.

4. Barnes G. Not without the couch: Eric Berne in basic differences between transactional analysis and psychoanalysis (2007) Trans Anal J 37: 41-50. https://doi.org/10.1177/036215370703700108

5. Berne E. Transactional analysis (1978) Ballantine Books, ISBN 0345271408 .

6. Dusay J. Egograms - How I see you and you see me (1977) Harper \& Row, New York.

7. Steiner CM. Scripts People Live: transactional analysis of life scripts (1990) Grove Pr. ISBN 0802132103.

8. Yokoyama $\mathrm{T}$ and Bando $\mathrm{H}$. The Egogram Feature of Late Teenager in the Internet Generation (2018) Clin Res Psychol 1:1-4. https://doi.org/10.33309/2639-9113.010201

9. Bando H. Psychological study of egogram can be helpful medically and socially for better life (2018) Archives Psych Behav Sci 1: 11-14.

10. Kuboki T, Nomura S, Wada M, Akabayashi A, Nagataki M, et al. Multidimensional assessment of mental state in occupational health care-combined application of three questionnaires: Tokyo University Egogram (TEG), Time Structuring Scale (TSS), and Profile of Mood States (POMS) (1993) Environ Res 61: 285-298. https://doi.org/10.1006/enrs.1993.1073

11. Yokoyama $T$ and Bando $H$. Characteristic egogram state of younger generation (2019) Edelweiss Psyi Open Access 3: 25-28. https://doi.org/10.33805/2638-8073.120

12. TEG group of Psychosomatic medicine, Tokyo Univ. Tokyo University. Egogram-New Ver. 3. 2020. Kaneko Publishing Company, Tokyo. Japan.

13. Psychological studies on line.

14. Berne E. Transactional analysis in psychotherapy: a systematic individual and social psychiatry (2015) Martino Fine Books, ISBN 161427844X.

15. Vos J and Rijn BV. A Systematic Review of Psychometric Transactional Analysis Instruments (2021) Transactional Analysis J 51: 127-159. https://doi.org/10.1080/03621537.2021.1904360

16. Yanagihara K, Kinugasa Y, Kunimi T, Kaneko S, Haruki N, et al. Child ego state and self-care behavior change in heart failure

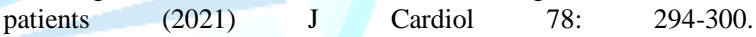
https://doi.org/10.1016/j.jicc.2021.05.006

17. Park B, Ibayashi K and Matsushita M. Classifying personalities of comic characters based on egograms (2018) Int Symp Affec Sci Eng 1-6. https://doi.org/10.5057/isase.2018-c000029

18. Schütte N, Blickle G, Frieder RE, Wihler A, Schnitzler F, et al The Role of Interpersonal Influence in Counterbalancing Psychopathic Personality Trait Facets at Work (2016) J Manag 44: 1338-1368. https://doi.org/10.1177/0149206315607967

19. Bando $\mathrm{H}$ and Yokoyama T. Psychological change in egogram for university student for years (2019) Asp Biomed Clin Case Rep 2: 48-51. https://doi.org/10.36502/2019/ASJBCCR.6159

20. Komatsu $\mathrm{H}$ and Rappleye J. Is exam hell the cause of high academic achievement in East Asia? The case of Japan and the case for transcending stereotypes (2018) British Edu Res J 1-25. https://doi.org/10.1002/berj.3468

21. Yoshiwara $\mathrm{K}$ and Tsuchiya $\mathrm{H}$. Correlations among focusing attitudes, psychological competitive abilities and public selfconsciousness in college athletes (2019) Person-Centered Exp Psycho 18 85-97. https://doi.org/10.1080/14779757.2019.1572028

22. Saitou T, Sugahara T and Kato C. A Study on the Self-Affirmation of University Student-Focusing on Classification by Personality (2018) 7th International Congress on Advanced Applied Informatics (IIAI-AAI). $\quad$ https://doi.org/10.1109/iiaiaai.2018.00110

23. Eun-Hyeon $\mathrm{J}$ and Dong-Hyung L. The effect of personality traits on stress and academic achievement (2018) Ind J Pub Health Res Dev 9: 1374-1379. $\quad$ https://doi.org/10.5958/09765506.2018.01183.X 